\title{
A systematic review of the risk factors for clinical response to opioids for all-age patients with cancer-related pain and presentation of the paediatric STOP pain study
}

Ersilia Lucenteforte ${ }^{1,2}$, Laura Vagnoli ${ }^{3}$, Alessandra Pugi ${ }^{4}$, Giada Crescioli ${ }^{1}$, Niccolò Lombardi ${ }^{1}$, Roberto Bonaiuti ${ }^{1}$, Maurizio Aricò ${ }^{5}$, Sabrina Giglio ${ }^{6,7}$, Andrea Messeri ${ }^{3}$, Alessandro Mugelli ${ }^{1}$, Alfredo Vannacci ${ }^{1+}$

and Valentina Maggini ${ }^{1,8^{*+}}$

\begin{abstract}
Background: Inter-patient variability in response to opioids is well known but a comprehensive definition of its pathophysiological mechanism is still lacking and, more importantly, no studies have focused on children. The STOP Pain project aimed to evaluate the risk factors that contribute to clinical response and adverse drug reactions to opioids by means of a systematic review and a clinical investigation on paediatric oncological patients.

Methods: We conducted a systematic literature search in EMBASE and PubMed up to the 24th of November 2016 following Cochrane Handbook and PRISMA guidelines. Two independent reviewers screened titles and abstracts along with full-text papers; disagreements were resolved by discussion with two other independent reviewers. We used a data extraction form to provide details of the included studies, and conducted quality assessment using the Quality Assessment Tool for Observational Cohort and Cross-Sectional Studies.
\end{abstract}

Results: Young age, lung or gastrointestinal cancer, neuropathic or breakthrough pain and anxiety or sleep disturbance were associated to a worse response to opioid analgesia. No clear association was identified in literature regarding gender, ethnicity, weight, presence of metastases, biochemical or hematological factors. Studies in children were lacking. Between June 2011 and April 2014, the Italian STOP Pain project enrolled 87 paediatric cancer patients under treatment with opioids (morphine, codeine, oxycodone, fentanyl and tramadol).

Conclusions: Future studies on cancer pain should be designed with consideration for the highlighted factors to enhance our understanding of opioid non-response and safety. Studies in children are mandatory.

Trial registration: CRD42017057740.

Keywords: Cancer pain, Children, Opioid efficacy, Opioid safety

\footnotetext{
*Correspondence: valentina.maggini@unifi.it

${ }^{\dagger}$ Alfredo Vannacci and Valentina Maggini contributed equally to this work.

'Department of Neuroscience, Psychology, Drug Research and Children's

Health, University of Florence, Florence, Italy

${ }^{8}$ Center for Integrative Medicine, Careggi University Hospital, Department of

Experimental and Clinical Medicine, University of Florence, Largo Brambilla, 3

- 50134 Florence, Italy

Full list of author information is available at the end of the article
}

(c) The Author(s). 2018 Open Access This article is distributed under the terms of the Creative Commons Attribution 4.0 International License (http://creativecommons.org/licenses/by/4.0/), which permits unrestricted use, distribution, and reproduction in any medium, provided you give appropriate credit to the original author(s) and the source, provide a link to the Creative Commons license, and indicate if changes were made. The Creative Commons Public Domain Dedication waiver (http://creativecommons.org/publicdomain/zero/1.0/) applies to the data made available in this article, unless otherwise stated. 


\section{Background}

Worldwide incidence of childhood cancer is about 160,000 new cases/year with 90,000 deaths/year under 15 years of age [1]. Young people with cancer experience multiple symptoms which negatively affect their quality of life [2]. Children with cancer often report pain (up to $89 \%$ of patients in an advanced stage of the disease) and over $70 \%$ of them sometimes report severe pain [3, 4]. Even though pain relief is one of the main concerns of physicians [5] and the inter-patient variability in response to opioids is well known [6], pain relief is still often misdiagnosed or treated inappropriately. In adults, current evidence suggests that several factors may influence analgesic response during the course of the illness [7]. For example, it has been reported that men require more morphine in the postoperative period than women [8] and obesity may partly explain inter-individual variations in opioid efficacy and toxicity [9]. Moreover, it is fundamental to consider the influence of genetic factors regulating opioid pharmacokinetics (e.g. UDP-glucuronosyltransferase genes, UGT) [10] and pharmacodynamics (e.g. $\mu$-opioid receptor gene, OPRM1) [11] on opioid response variability. In this frame, the region of Tuscany (Italy) developed a research program ("Pharmacogenetics in pain therapy") in 2006 to evaluate the association between single nucleotide polymorphisms (SNPs) in metabolizing genes and the response to opioids in a general population. To the best of our knowledge, no similar epidemiological and genetic study has yet been conducted to address these important issues in paediatric populations even if physiological differences between adults and children are well known [12]. Furthermore, children experience illnesses and are subjected to medical care differently from adults and they depend on their parents to cope with stressful situations [13]. Therefore, familiar context may be an influencing factor on the perception of pain and the efficacy of pain therapy.

For these reasons, in 2010 we designed a longitudinal study focused only on paediatric cancer patients, called STOP Pain (Suitable Treatment for Oncologic Paediatric Pain) to continue recruitment for the regional study in an attempt to get as homogeneous a sample as possible, i.e. patients from the same population (with cancer pain) and treated in a homogeneous way. The main objectives of the project are to conduct a comprehensive literature review of the association between inter-individual opioid responsiveness, socio-demographic and medical factors and to evaluate the risk factors that contribute to response/non-response and adverse drug reactions to opioids in a sample of paediatric oncological patients.

\section{Methods}

\section{Systematic review of current literature}

This review was performed in accordance with the Cochrane Handbook and the Prisma Statement for Systematic Reviews [14] and it was registered in PROSPERO with the number CRD42017057740 [15].
A systematic PUBMED and EMBASE search for any study evaluating opioid non-response and safety among cancer patients was performed up to the 24th of November 2016. Four themes (drugs, cancer, randomized clinical trials, and observational studies) were combined by using the Boolean operator "and" (see full search strategy in Additional file 1). We took into consideration articles (excluding letters) published in English and Italian, and studies on humans using the corresponding filters. We also searched the papers among those quoted as references in the retrieved studies, as well as in a few previous reviews.

Two investigators (AP and GC) independently reviewed titles and abstracts, and selected articles. Any disagreements was resolved through discussion and consensus with two other independent reviewers (EL and VM).

In a second phase, we retrieved the full texts and selected the original articles based on the following criteria:

1) Patients included were cancer patients

2) Drugs involved were opioids

3) Outcomes evaluated were opioid non-response and safety (see Additional file 2)

4) One or more variables were studied as factors associated to therapy outcome

We decided not to consider putative genetic factors since a large body of evidence was already available. Moreover, we excluded pharmacokinetic studies as well as clinical trials and comparative studies evaluating different drugs, drug doses, formulations and administration routes.

For each retrieved study, we extracted the following data: location, year of publication, study type, size, mean age and gender of the sample, tumor characteristics, drugs used and main findings.

The quality of the included studies was assessed using the "Quality Assessment Tool for Observational Cohort and Cross-Sectional Studies" [16] following the criteria reported in Additional file 3.

\section{STOP pain project}

The study enrolled paediatric patients receiving opioids (morphine, codeine, oxycodone, fentanyl and tramadol) for cancer-related pain relief between June 2011 and April 2014. The institutional review board of Meyer Children's Hospital approved the study.

Two structured questionnaires were administered to the enrolled children or their parents after obtaining written informed consent. The first questionnaire included demographic information (e.g. age, gender, weight, height, and allergies), medical history, concomitant illnesses and lifestyle of the children. Data concerning cancer diagnosis and evolution of the disease were collected from medical records. Data on health conditions as well as other parameters potentially predictive of high or low treatment 
responsiveness were collected carefully with the aim of adjusting for any confounding variables and/or effect modifiers. The second questionnaire included demographic information on parents and family environment.

An Individual Case Report Form (CRF) recorded all data. Unique Patient Code anonymized the patient before the matching with genetic data. Peripheral blood or mouth swab (when possible) were collected after patient recruitment. DNA was isolated using EZ1 Extractor (Qiagen) and standard commercial kits. DNA concentration and purity was then measured with NanoDrop 2000 (Thermo Scientific) and stored at $-20{ }^{\circ} \mathrm{C}$. Genotyping was carried out using the Taqman assay (ABI, Applied Biosystems, Foster City, CA). Taqman probes were designed and synthesized by Applied Biosystems, who also provided standard PCR profile and reaction conditions. PCR plates were read on a 7500 Fast Real Time PCR system (Applied Biosystems).

Opioid dosing was standardized through the conversion to intravenous (IV) morphine equivalents (ME) according to the following opioid equi-analgesic calculation [17]: IV ME = oral oxycodone $* 2 / 3=I V$ tramadol $* 10=$ oral tramadol $* 30=$ oral codeine $* 30=I V$ fentanyl $/ 100$. When the direct conversion factor to IV ME was not available, the dosage was first converted to oral morphine equivalents and then to IV ME (3:1). Data are presented as mean and standard deviation.

We considered the following two outcomes regarding dose: dose $(\mathrm{mg} / \mathrm{kg})$ of IV ME administered during the first $24 \mathrm{~h}$ of treatment $\left(\right.$ Dose $\left._{24 \mathrm{~h}}\right)$ and total dose $(\mathrm{mg} / \mathrm{kg}$ ) of IV ME (Dose tot $_{\text {). }}$.

The Visual Analogue Scale (VAS) was compiled by children of older age (>6 yrs). Wong \& Baker FACES Pain Rating Scale was administered to children between 4 and 6 years of age as an alternative outcome measure. When self-reporting of pain was not possible, such as in children who had difficulty verbalizing the presence or intensity of pain, the FLACC scale was used. Nurses administered the scales for pain intensity to patients at the first examination, repeating the procedure eight-hourly for intra-individual pain intensity evaluation.

We considered the following three outcomes regarding pain intensity: pain intensity before treatment $\left(\mathrm{PI}_{\mathrm{to}}\right)$; difference between pain intensity after $24 \mathrm{~h}$ of treatment and $\mathrm{PI}_{\text {to }}$ $\left(\Delta_{\text {VAS }}\right)$; time to reach the lowest possible pain intensity $\left(\right.$ Time $\left._{\text {tot }}\right)$.

Evaluated side effects were gastrointestinal effects (nausea/vomiting, diarrhea and constipation), central nervous system effects (agitation, drowsiness, headache and sedation), and all adverse effects (gastrointestinal and central nervous system effects, and itching).

We checked data for consistency and completeness by tabulating the variables of interest. We compared differences for mean values of continuous response variables by one-way ANOVA and differences for percentages of categorical variables by chi-square test.

\section{Results}

\section{Systematic review}

The PUMBED and EMBASE search produced 9847 records. A review of titles and abstracts resulted in the selection of 336 records of original studies, among which 72 met the inclusion criteria. Figure 1 reports the flowchart of study selection.

The characteristics of 74 studies included in this review [18-91] are reported in Additional file 2. Thirty-three studies were conducted in Europe, 16 in Asia, 22 in North America, one in South America (Brazil) and two in Turkey. Eighteen studies were published before 2000; 61 studies were conducted on more than 50 patients; two studies were conducted on female patients, two others mainly on males, and in the remaining studies the proportions of the two genders were similar. Four studies were conducted on children. The studies reported a broad variety of opioid non-response outcomes, and only a few outcomes were evaluated in more than two trials. In particular, non-response was defined as high dosage or pain intensity, low pain control or relief, switching, high Opioid Escalation Index (OEI) percentage, or worsening of pain. Patients used more than one opioid or non-specified opioids in 41 studies. Morphine was used alone in 19 studies, oxycodone alone in six, methadone alone in three and fentanyl alone in four studies. More than half of the included studies (41 out of 74) reported the opioid doses in milligrams of morphine equivalents.

For the included studies, the assessment of methodological quality was performed (Additional file 4) using the Quality Assessment Tool for Observational Cohort and Cross-Sectional Studies [16]. Items 1, 4, 6, 7, 9, 10, 11 and 13 have received affirmative responses from $100 \%$ of the studies included in the analysis. More than $50 \%$ of studies clearly defined the population analyzed (item 2) and performed an adjusted statistical analysis for confounding variables (item 14). Not reported (NR) was the answer to items 3 and 5 respectively in 58 and $99 \%$ of included studies, while not applicable (NA) was assigned for more than $50 \%$ of studies for items 8 and 12 .

Given the high number of factors considered, we decided to report only the results on associations investigated in more than three studies and found in 39 studies including more than 50 subjects and published after 2000 (Table 1). With regard to socio-demographic factors, while no association was found with age in nine studies, nine other studies reported an inverse association (i.e. older patients had a better response compared to younger ones) while three found a direct one. Gender was not related to non-response in 15 studies, two studies reported that males had a worse response than females, while one study stated that they had a better one. Body mass index (BMI) was investigated in two studies with no notable relationship found, while a direct association between non-response and weight gain was 


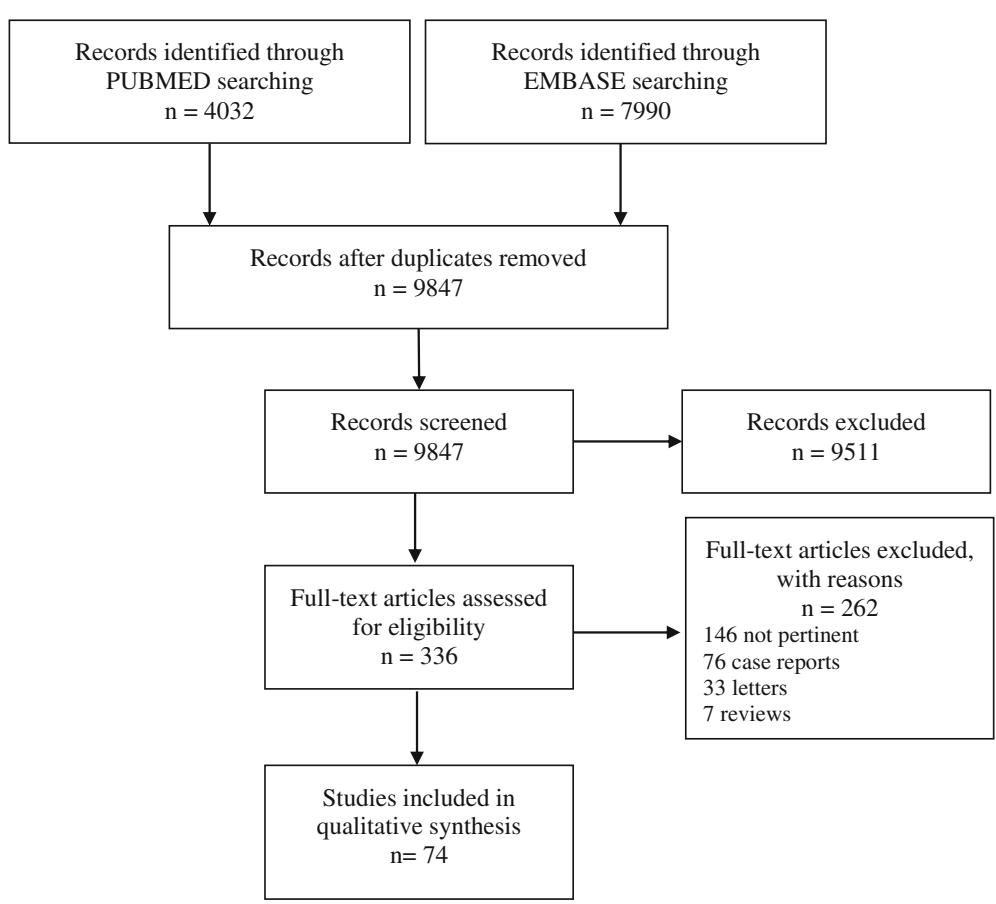

Fig. 1 PRISMA Flow diagram

reported in one study (i.e. patients with high weight had a worse response compared to low-weight patients). Finally, two studies reported no association with alcoholism and one a direct association with alcohol abuse (i.e. subjects who abused alcohol had a worse response compared to those with normal drinking habits).

Cancer diagnosis, biochemical parameters, cognition, metastases location, psychological distress, and sleep disturbances were the clinical factors studied, with high heterogeneity of specific measures investigated and no clear association with outcomes. However, patients with lung cancer or mesothelioma (three out of 16 studies) or gastrointestinal cancer (two studies) had a worse response (direct association), as did patients with anxiety (two studies), or sleep disturbance (two out of four studies).

Pain-related factors were investigated and two studies reported a direct association between breakthrough cancer pain and worse response (i.e. subjects with breakthrough pain had a worse response), while one study reported no association. Similarly, two studies reported a direct association with incidental pain while two others found no association.

High heterogeneity emerged for measures of pain intensity and with regard to pain pathophysiology (neuropathic, visceral, somatic, etc.) with no clear association, although four out of 11 studies reported a direct association between the presence of neuropathic pain and opioid non-response.
Finally, analgesic drugs, adjuvants and other drugs were often studied as possible factors associated with non-response but contrasting results were reported.

Results on predictive factors of opioid safety are shown in Table 2.

Compared to younger patients, older ones reported a lower rate of myoclonus, urinary hesitancy, dry mouth, and nausea. No notable relationship was found between gender and itch, myoclonus, nausea, urinary hesitancy and constipation nor between age and anorexia, itch, nausea, constipation, confusion, or drowsiness, whereas anorexia and dry mouth were more common in female patients and constipation, dry mouth, and hallucinations were more frequent in older patients in only one study. We found no relationship between most clinical factors (i.e. biochemical parameters, cancer diagnosis and terminal stage) and the occurrence of adverse events although constipation was related to low glomerular filtration rate (GFR), comorbidity and terminal stage, as well as to confusion and drowsiness. The presence of neuropathic or somatic pain was related to the onset of confusion and dry mouth; while visceral pain was associated with a high frequency of dry mouth and gastrointestinal symptoms.

No significant differences in side effects were observed regarding anorexia, somnolence, nausea, vomiting, constipation, dry mouth, and emesis despite high opioid doses. However, an inverse association was found between opioid dose and dry mouth, while one study reported a direct association with urinary hesitancy. One study found a direct 


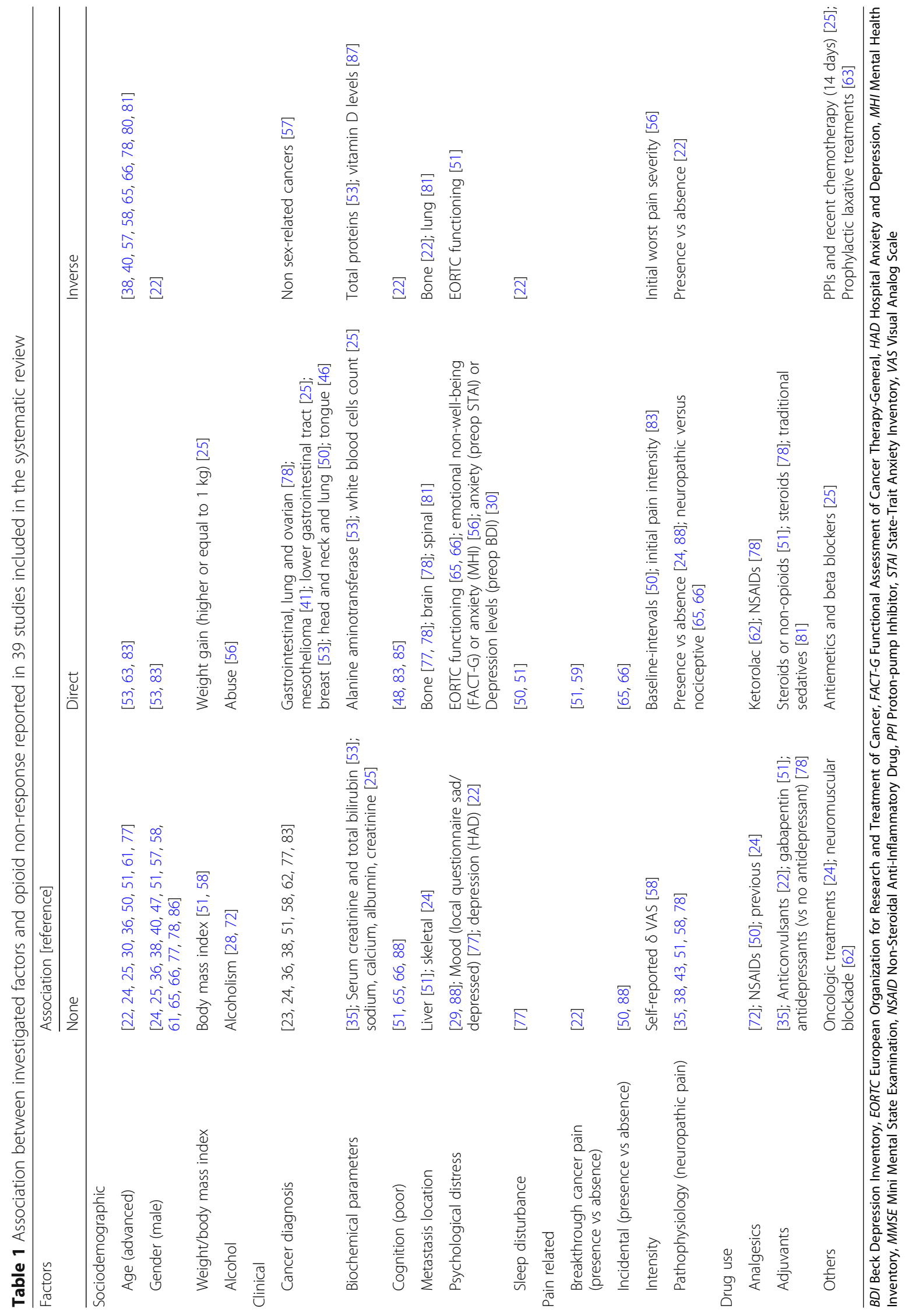




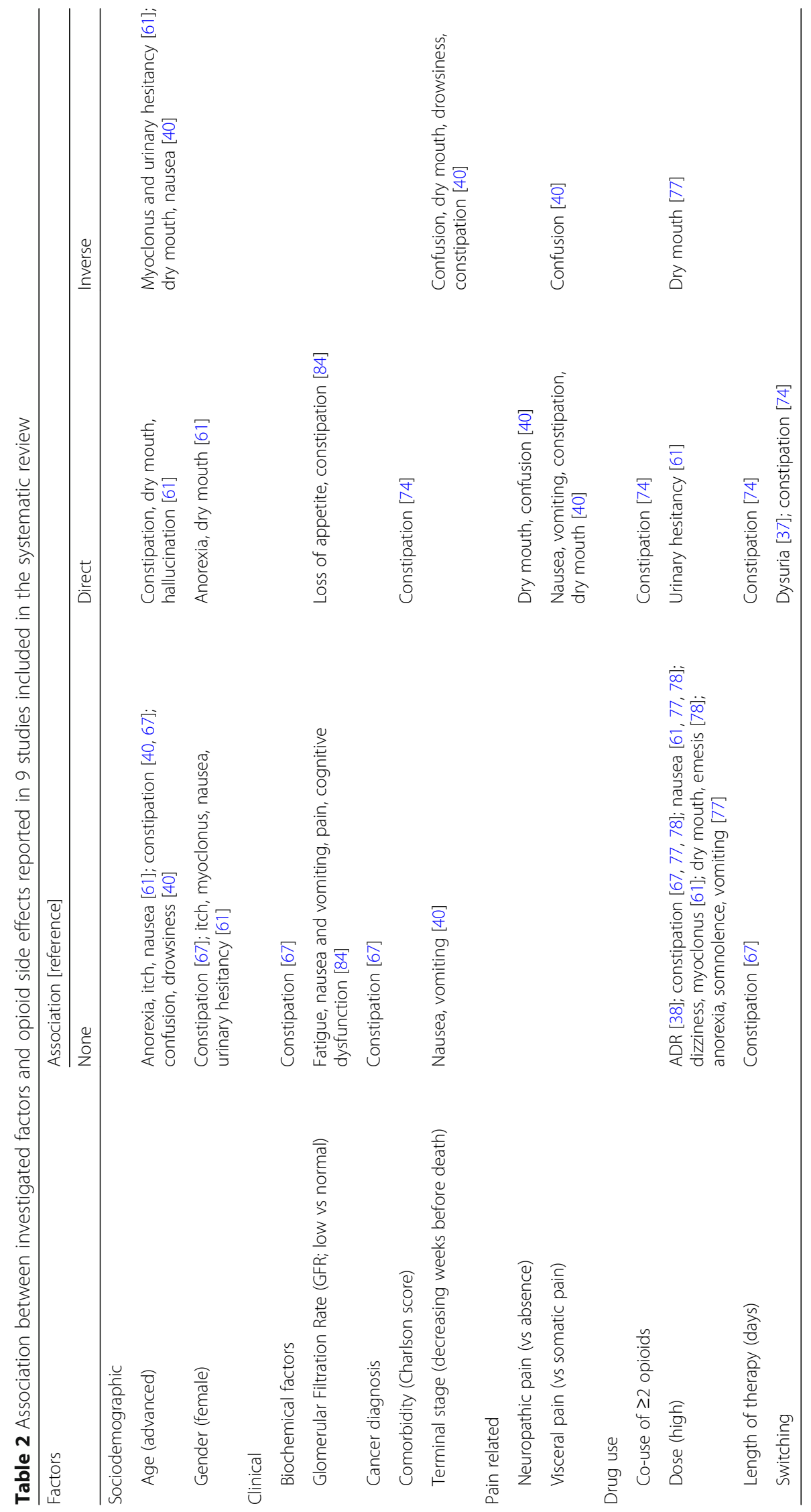


association between the length of opioid therapy and concomitant use of more than two opioids and the onset of constipation; nevertheless, the association was denied in another study. A direct relationship was found between opioid switching, dysuria, and constipation.

Validation of the Prisma checklist for the systematic review is reported in Additional file 5.

\section{STOP pain project}

One hundred twenty-nine $(75+54)$ patients met the inclusion criteria and resulted eligible for the study. Informed consent was requested from parents of 54 children but they were not included in the study for the following reasons: refusals $(n=6)$, terminally ill patients $(n=9)$, early discharge $(n=7)$, hospitalization in sterile room $(n=7)$, non-Italian speaking parents $(n=25)$.

The data set consisted of the characteristics of $87 \mathrm{pa}-$ tients enrolled between June 2011 and April 2014. For seven patients the biological sample was not available. STAI test was completed by 40 parents (37 mothers).

Table 3 presents the distribution of selected characteristics among 87 cancer patients included in the STOP Pain Project. The majority of children were male (56.32\%) with more than 3 years of age (36.78\% between 3 and 12 years, $42.53 \%$ over 12 ), and a BMI of more than $15 \mathrm{~kg} / \mathrm{m}^{2}$ (44.83\% between 15 and $20 \mathrm{~kg} / \mathrm{m}^{2}, 25.29 \%$ more than 20 ). Cancer diagnoses were mainly leukemia and lymphoma (39.08), sarcoma $(20.69 \%)$ or osteosarcoma $(19.54 \%)$, in $26.44 \%$ of cases with metastases, with oral cavity (49.43\%) or skeletal $(16.09 \%)$ pain. Patients were treated with morphine (68.97\%), tramadol (21.84\%), oxycodone (2.30\%), codeine $(2.30 \%)$ and more than one opioid $(4.60 \%)$ for the achievement of pain relief. Table 4 shows the selected outcomes to evaluate opioid responsiveness of the 87 patients in terms of opioid dosage requirements and pain intensity assessment.

The aim of the present study was to investigate patient's genetic predisposing trait (single nucleotide polymorphisms of genes involved in opioid transport, target and metabolism) to opioid responsiveness and safety profile. The investigated genes were $\boldsymbol{A B C B 1}$ (ATP binding cassette subfamily $\mathrm{B}$ member 1 ), COMT (catecho1-O-methyltransferase), IL6 and IL8 (interleukin 6 and 8), KCNJ6 (potassium inwardly-rectifying channel, subfamily J, member 6), NR1I2 (nuclear receptor subfamily 1 group I member 2), OPRM1 (opioid receptor, mu 1), TNF- $\alpha$ (tumor necrosis factor $\alpha$ ) and UGT2B7 (UDP glucuronosyltransferase 2 family, polypeptide B7). For SNP selection, high priority was given to those SNPs for which functional alteration data were available in the literature and the minor allele frequency is above $15 \%$ in the Caucasian population.
Table 3 Demographic and clinical characteristics of 87 patients

\begin{tabular}{|c|c|c|}
\hline & Number & Percent \\
\hline \multicolumn{3}{|l|}{ Gender } \\
\hline Male & 49 & 56.32 \\
\hline Female & 38 & 43.68 \\
\hline \multicolumn{3}{|l|}{ Age (months) } \\
\hline $0-36$ & 18 & 20.69 \\
\hline$>36-144$ & 32 & 36.78 \\
\hline$>144$ & 37 & 42.53 \\
\hline \multicolumn{3}{|l|}{ BMI } \\
\hline$<15$ & 25 & 28.74 \\
\hline $15-<20$ & 39 & 44.83 \\
\hline$\geq 20$ & 22 & 25.29 \\
\hline missing & 1 & 1.15 \\
\hline \multicolumn{3}{|l|}{ Diagnosis } \\
\hline Brain Tumor & 6 & 6.90 \\
\hline Leukemia and Lymphoma & 34 & 39.08 \\
\hline Neuroblastoma & 6 & 6.90 \\
\hline Osteosarcoma & 17 & 19.54 \\
\hline Sarcoma & 18 & 20.69 \\
\hline Others & 6 & 6.90 \\
\hline \multicolumn{3}{|l|}{ Metastasis } \\
\hline No & 64 & 73.56 \\
\hline Yes & 23 & 26.44 \\
\hline
\end{tabular}

\section{Discussion}

\section{Systematic review}

The large inter-individual variability in response to opioid analgesia and high prevalence of adverse events associated with their use underline the clinical importance of being able to predict who will or will not respond to opioid treatment.

\section{Patient characteristics}

According to our review, opioid non-response is associated with age in that older patients had a better response (inverse association). This result can be found in the majority of studies that show that elderly patients present an increased sensitivity to opioids [40]. Indeed, as age increases, there is a decrease in the volume of distribution and clearance of morphine, as well as a decrease in plasma albumin-the latter resulting in a greater unbound fraction of drug. These pharmacokinetic factors will lead to higher plasma levels and a longer duration of morphine action in elderly compared to younger patients receiving the same dose of the drug. In contrast with the widely reported sex-related differences in opioid response [92], we found no influence of gender. In particular, according to literature, females are more sensitive to morphine than males [93] while pain perception is reported to increase with the 
Table 4 Pain intensity assessment and opioid dosage requirements of the 87 patients

\begin{tabular}{|c|c|c|}
\hline & \multicolumn{2}{|c|}{ mean $\pm S D$} \\
\hline $\mathrm{PI}_{\text {to }}$ (Pain Intensity at $\mathrm{t}_{0}$ ) & \multicolumn{2}{|c|}{$4.34 \pm 2.17$} \\
\hline $\mathrm{Pl}_{24 \mathrm{~h}}$ (Pain intensity at $\mathrm{t}_{24 \mathrm{~h}}$ ) & \multicolumn{2}{|c|}{$2.04 \pm 2.56$} \\
\hline $\mathrm{Pl}_{\text {end }}$ (Pain intensity at $\mathrm{t}_{\text {end }}$ ) & \multicolumn{2}{|c|}{$1.07 \pm 2.19$} \\
\hline \multirow[t]{2}{*}{ Time $_{\text {tot }}$ (time to the minor PI) } & \multicolumn{2}{|c|}{$140.43 \pm 63.89$} \\
\hline & $\mathrm{N}$ & $\%$ \\
\hline \multicolumn{3}{|l|}{$\mathrm{PI}_{\text {to }}$ (grouped) } \\
\hline$\leq 4$ & 47 & 54.02 \\
\hline$>4$ & 40 & 45.98 \\
\hline \multicolumn{3}{|l|}{$\Delta_{\mathrm{VAS}}\left(\mathrm{PI}_{\mathrm{tO}}-\mathrm{Pl}_{\mathrm{t} 24 h} ;\right.$ grouped $)$} \\
\hline$\leq 2$ & 46 & 52.87 \\
\hline$>2$ & 39 & 44.83 \\
\hline \multicolumn{3}{|l|}{ Responders ( $\mathrm{Pl}_{\text {end }}$ equal to 0 ) } \\
\hline No & 23 & 26.44 \\
\hline Yes & 64 & 73.56 \\
\hline \multicolumn{3}{|l|}{ Pain location } \\
\hline Abdominal & 12 & 13.79 \\
\hline Oral cavity & 43 & 49.43 \\
\hline Skeletal - Muscle & 14 & 16.09 \\
\hline Other & 18 & 20.69 \\
\hline \multicolumn{3}{|l|}{ Drug } \\
\hline morphine & 60 & 68.97 \\
\hline tramadol & 19 & 21.84 \\
\hline oxycodone & 2 & 2.30 \\
\hline codeine & 2 & 2.30 \\
\hline more than one & 4 & 4.60 \\
\hline \multicolumn{3}{|l|}{$\operatorname{Dose}_{24 h}(\mathrm{mg} / \mathrm{kg})$} \\
\hline$\leq 0.2$ & 24 & 27.59 \\
\hline $0.2-\leq 0.42$ & 20 & 22.99 \\
\hline $0.42-\leq 0.50$ & 22 & 25.29 \\
\hline$>0.50$ & 19 & 21.84 \\
\hline Missing & 2 & 2.30 \\
\hline \multicolumn{3}{|l|}{ Dose $_{\text {tot }}(\mathrm{mg} / \mathrm{kg})$} \\
\hline$\leq 1.2$ & 21 & 24.14 \\
\hline $1.2-\leq 2.16$ & 20 & 22.99 \\
\hline $2.16-\leq 3.42$ & 24 & 27.59 \\
\hline$>3.42$ & 22 & 25.29 \\
\hline
\end{tabular}

lowering of estrogen levels (such as in menopause) [94], suggesting that aging might contribute to level the gender differences in opioid response. This could explain the lack of association between gender and non-response found in our review since all included studies enrolled patients over the age of 60 and did not take into account menopausal status.

\section{Type of cancer}

We also found that patients with lung or gastrointestinal cancer had a worse response to opioid analgesia (direct association). Most surveys on cancer pain have not assessed the effect of primary diagnosis on the incidence, intensity, and treatment of cancer pain since the assessment of these effects is often complicated by the existence of multiple medical problems. The current evidence emerging mainly from studies conducted in palliative care units suggests that somatic pain is associated with lung, head and neck, breast, and prostate cancer, while visceral pain is associated with colorectal, gastric, liver, pancreatic, and uterine cancer [41]. Moreover, primary gastrointestinal and lung carcinomas, as well as metastatic bone disease, ovarian carcinoma, and brain tumors are often associated with high and very high morphine dosages [76].

\section{Psychological factors}

Patients with anxiety or sleep disturbance had a worse response (direct association). Psychological distress is often assessed by patients themselves via several health-related quality of life tools and in particular the EORTC QLQ-C30 (emotional functioning scale), a test able to assess many psychological parameters, including major depression, anxiety, or hostility that can make treatment more difficult [75]. Untreated anxiety has a negative impact on the management of cancer pain [95]. Sleep disturbances can be generated by anxiety but they might also be independent, thus more detailed information on sleep quality through specific sleep questionnaires (e.g. Pittsburgh Sleep Quality Index) could add further information [51].

\section{Pain characteristics}

Patients with neuropathic or breakthrough pain had a worse response (direct association). Breakthrough pain, including incidental pain, is a transient exacerbation of pain that occurs either spontaneously or in relation to a specific predictable or unpredictable trigger [96]. Neuropathic pain is defined as the pain caused by a lesion in the peripheral or central nervous system resulting from cancer or other causes such as chemotherapy. Despite significant progress in cancer research, few data are available yet on the pathophysiology of neuropathic pain due to cancer. The management of neuropathic pain is often inadequate and analgesic therapies need to be supported by adjuvants, such as anticonvulsants drugs, corticosteroids and antidepressants [97].

\section{Other drugs}

No clear association was found between the use of other drugs and opioid non-response. The use of nonsteroidal anti-inflammatory drugs (NSAIDs) and steroids is recommended in combination with weak or low dose opioids. 
Therefore, their usage may be directly linked to non-response because of poor treatment. On the other hand, proton pump inhibitors and laxatives might be prescribed to relieve adverse effects induced by high dose opioids. The use of these drugs may enhance response when concomitantly prescribed with high dose or strong opioids.

While some preliminary data were available, the relationship between non-response and cancer site, presence and location of metastases, and cognition was not defined.

In light of these results, we strongly suggest that future studies on cancer pain be designed with the specific aim of enhancing our understanding of opioid non-response and safety. Further information could be obtained through individual patient data meta-analysis, however it could be burdensome per se and problematic due to the low quality of original papers as well as the heterogeneity of the definition of "non-response" reported in the studies conducted up to now.

Moreover, the use of morphine dose to define drug response might be questionable. In our opinion, more efforts should be made to include proper treatment response evaluations, which can assess the real decrease in pain intensity through use of validated instruments, and not only through drug dose as a proxy. Further efforts should be made to precisely and routinely measure cancer pain in the strictest and most reliable manner available. This issue could be properly approached by clinicians according to Evidence Based Medicine parameters and not, as often still happens, according to their personal beliefs, hospital tradition or to unreliable self-reporting instruments.

\section{Strengths of this systematic review}

- A comprehensive and robust systematic review in accordance with Cochrane Handbook and PRISMA guidelines.

- Search of two electronic database and assessment of the methodological quality of the included studies.

- All reviewing and data extraction was carried out by one author and double-checked by a second author; two other independent reviewers discussed and resolved any disagreement.

- Evaluation of a broad range of risk factors contributing to clinical response and adverse drug reactions to opioids.

\section{Limitations of the systematic review}

- Definition of "non-response" reported in the studies included in the systematic review was heterogeneous.

\section{STOP pain project}

In an effort to overcome the above mentioned problems, a longitudinal, nation-wide, paediatric study was planned by the Department of Neuroscience, Psychology, Drug Research and Children's Health of the University of Florence, Italy and Anna Meyer Children's University Hospital (Florence, Italy) entitled "STOP Pain - Suitable Treatment for Oncologic Paediatric Pain".

In particular, the study uses more than one outcome to evaluate opioid responsiveness in terms of both opioid dosage and pain intensity assessment. This point raises the challenge of selecting a proper outcome measure of pain since it is a subjective experience that might be quite difficult to quantify [98]. In 2010, the AIRC (Italian Association for Cancer Research) financed this research program with the aim to evaluate the association between genetic factors and response to opioids in children. STOP Pain, comprehensive of the previous literature review, was a pilot study attempting to propose specific definition of clinical outcomes and their associated factors in a homogenous population (i.e. paediatric cancer-related pain patients). In fact, the main limitation of the study was the number of enrolled patients even if many of them were treated in a homogeneous way, i.e. titration of morphine by continuous infusion (60 out of 87 ).

Moreover, since children suffer from different types of cancer pain, the fact we did not characterize the nature of such pain (i.e. nociceptive, neuropathic, procedural, etc.) could represent another point of weakness of our study. Nevertheless, in some disease conditions, as well as in cancer, patients may have mixed pain consisting of somatic, visceral and neuropathic pain all at the same time or each separately at different times [99]. Clinical distinction between nociceptive and neuropathic pain is based on the anatomic origin of the stimulus, which was not clearly identifiable based on clinical data available for our pediatric patients.

In any case, planning of multicentric studies is pivotal to reach the appropriate sample size to address multiple comparison problems and capture minor genetic effects.

\section{Conclusions}

It is our hope that the design of larger studies will consider the factors highlighted in the present work to enhance the understanding of opioid non-response and safety. And finally, we wish to underscore the necessity for studies on children in this field.

\section{Additional files}

Additional file 1: BMC Cancer.doc, Full Search Strategy. (DOCX 17 kb)

Additional file 2: BMC Cancer.doc, Characteristics of the 74 studies included in the review. (RTF $506 \mathrm{~kb}$ )

Additional file 3: BMC Cancer.doc, Criteria for the quality assessment of the included studies in the review. (DOCX $62 \mathrm{~kb}$ ) 
Additional file 4: BMC Cancer.doc, The assessment of methodological quality for the included studies in the review. (DOC $174 \mathrm{~kb}$ )

Additional file 5: BMC Cancer.doc, PRISMA Checklist for the current review. (DOC $58 \mathrm{~kb}$ )

\section{Acknowledgements}

STOP Pain was initiated by the Tuscany Region and was supported by the Associazione Italiana per la Ricerca sul Cancro (AIRC): their support was greatly appreciated. We also wish to thank the Meyer Children's Hospital's staff, all the patients, and their parents.

\section{Funding}

This work was supported by the Associazione Italiana per la Ricerca sul Cancro (AIRC) grant number [10465]. The funding body had no role in the design of the study and collection, analysis, and interpretation of data and in writing the manuscript.

\section{Availability of data and materials}

All data generated or analyzed for the present review are included in this article and its Additional file 1, Additional file 2, Additional file 3, Additional file 4, Additional file 5. The datasets generated and analyzed during the STOP Pain project are available from the authors upon reasonable request.

\section{Authors' contributions}

VM: PI of the STOP Pain study; VM, EL: conception and design of the work; MA AMe: patients recruitment; LV, GC, AP, RB, NL: data collection; EL, VM, AV: data analysis and interpretation; EL, VM, GC, AP: drafting the article; EL, VM, AV, AMu, SG: critical revision of the article. All authors discussed the results and implications of the manuscript approving the publication of the final version.

\section{Ethics approval and consent to participate}

The STOP Pain study obtained ethics approval from the institutional review board of Meyer Children's Hospital (Protocol letter 9116/2010, December 14, 2010). Written informed consent to participate in the study was obtained from each patient (or their parent or legal guardian).

\section{Competing interests}

The authors declare that they have no competing interests.

\section{Publisher's Note}

Springer Nature remains neutral with regard to jurisdictional claims in published maps and institutional affiliations.

\section{Author details \\ 'Department of Neuroscience, Psychology, Drug Research and Children's Health, University of Florence, Florence, Italy. ${ }^{2}$ Department of Clinical and Experimental Medicine, University of Pisa, Pisa, Italy. ${ }^{3}$ Pain and Palliative Care Unit, Meyer children's hospital, Florence, Italy. ${ }^{4}$ Clinical Trial Office, Meyer Children's Hospital, Florence, Italy. ${ }^{5}$ Direzione Generale, Azienda Sanitaria Provinciale, Ragusa, Italy. ${ }^{6}$ Medical Genetics Unit, Meyer Children's University Hospital, Florence, Italy. ${ }^{7}$ Medical Genetics Unit, Department of Clinical and Experimental Biomedical Sciences "Mario Serio", University of Florence, Florence, Italy. ${ }^{8}$ Center for Integrative Medicine, Careggi University Hospital, Department of Experimental and Clinical Medicine, University of Florence, Largo Brambilla, 3 - 50134 Florence, Italy.}

\section{Received: 1 March 2018 Accepted: 2 May 2018}

\section{Published online: 18 May 2018}

References

1. Ferlay JBF, Pisani P, Parkin DM. GLOBOCAN 2002: Cancer incidence, Mortality and prevalence worldwide, vol. 5; 2004.

2. Hechler T, Wager J, Zernikow B. Chronic pain treatment in children and adolescents: less is good, more is sometimes better. BMC Pediatr. 2014;14:262.

3. Zernikow B, Hasan C, Hechler T, Huebner B, Gordon D, Michel E. Stop the pain! A nation-wide quality improvement programme in paediatric oncology pain control. Eur J Pain. 2008;12(7):819-33.

4. Mercadante S, Giarratano A. Pharmacological management of cancer pain in children. Crit Rev Oncol Hematol. 2014;91(1):93-7.
5. World Health Organization. Cancer pain relief and palliative care in children. Geneva: World Health Organization; 1998. http://www.who.int/iris/handle/10665/42001. Accessed 23 Apr 2018

6. Corli O, Roberto A, Greco MT, Montanari M. Assessing the response to opioids in cancer patients: a methodological proposal and the results. Support Care Cancer. 2015:23(7):1867-73.

7. Mercadante S, Adile C, Torta R, Varetto A, Fulfaro F, Giarratano A, Casuccio A. Meaningful cut-off pain intensity for breakthrough pain changes in advanced cancer patients. Curr Med Res Opin. 2013;29(1):93-7.

8. Periasamy S, Poovathai R, Pondiyadanar S. Influences of gender on postoperative morphine consumption. J Clin Diagn Res. 2014;8(12):GC04-7.

9. Lloret Linares C, Decleves X, Oppert JM, Basdevant A, Clement K, Bardin C, Scherrmann JM, Lepine JP, Bergmann JF, Mouly S. Pharmacology of morphine in obese patients: clinical implications. Clin Pharmacokinet. 2009; 48(10):635-51.

10. Fladvad T, Klepstad P, Langaas M, Dale O, Kaasa S, Caraceni A, Skorpen F. Variability in UDP-glucuronosyltransferase genes and morphine metabolism: observations from a cross-sectional multicenter study in advanced cancer patients with pain. Pharmacogenet Genomics. 2013:23(3):117-26.

11. Hwang IC, Park JY, Myung SK, Ahn HY, Fukuda K, Liao Q. OPRM1 A118G gene variant and postoperative opioid requirement: a systematic review and meta-analysis. Anesthesiology. 2014;121(4):825-34.

12. Neal-Kluever A, Aungst J, Gu Y, Hatwell K, Muldoon-Jacobs K, Liem A, Ogungbesan A, Shackelford M. Infant toxicology: state of the science and considerations in evaluation of safety. Food Chem Toxicol. 2014;70: $68-83$

13. Patenaude AF, Last B. Cancer and children: where are we coming from? Where are we going? Psycho-Oncology. 2001;10(4):281-3.

14. Moher D, Liberati A, Tetzlaff J, Altman DG, Group P. Preferred reporting items for systematic reviews and meta-analyses: the PRISMA statement. BMJ (Clin Res Ed). 2009;339:b2535.

15. PROSPERO: International prospective register of systematic reviews. [https:// www.crd.york.ac.uk/PROSPERO/].

16. Quality Assessment Tool for Observational Cohort and Cross-Sectional Studies https://www.nhlbi.nih.gov/health-topics/study-quality-assessmenttools. Accessed 23 Apr 2018

17. American College of Physicians. ACP internist: dosing and conversion chart for opioid analgesics. www.acpinternistorg/archives/2004/12/pain/dosing_ convpdf 2004. Accessed 23 Apr 2018.

18. Yang JC, Clark WC, Tsui SL, Ng KF, Clark SB. Preoperative multidimensional affect and pain survey (MAPS) scores predict postcolectomy analgesia requirement. Clin J Pain. 2000;16(4):314-20.

19. Vigano A, Bruera E, Suarez-Almazor ME. Age, pain intensity, and opioid dose in patients with advanced cancer. Cancer. 1998;83(6):1244-50.

20. Takase H, Sakata T, Yamano T, Sueta T, Nomoto S, Nakagawa T. Advantage of early induction of opioid to control pain induced by irradiation in head and neck cancer patients. Auris Nasus Larynx. 2011:38(4):495-500.

21. Syrjala KL, Chapko ME. Evidence for a biopsychosocial model of cancer treatment-related pain. Pain. 1995:61(1):69-79.

22. Stromgren AS, Groenvold M, Petersen MA, Goldschmidt D, Pedersen L, Spile M, Irming-Pedersen G, Sjogren P. Pain characteristics and treatment outcome for advanced cancer patients during the first week of specialized palliative care. J Pain Symptom Manag. 2004;27(2):104-13.

23. Salminen EK, Silvoniemi M, Syrjanen K, Kaasa S, Kloke M, Klepstad P. Opioids in pain management of mesothelioma and lung cancer patients. Acta Oncol. 2013;52(1):30-7.

24. Ripamonti Cl, Campa T, Fagnoni E, Brunelli C, Luzzani M, Maltoni M, De Conno F. Normal-release oral morphine starting dose in cancer patients with pain. Clin J Pain. 2009;25(5):386-90.

25. Riley J, Ross JR, Rutter D, Wells AU, Goller K, du Bois R, Welsh K. No pain relief from morphine? Individual variation in sensitivity to morphine and the need to switch to an alternative opioid in cancer patients. Support Care Cancer. 2006;14(1):56-64

26. Rees WD. Opioid needs of terminal care patients: variations with age and primary site. Clin Oncol (R Coll Radiol). 1990;2(2):79-83.

27. Pickar D, Cohen MR, Dubois M. The relationship of plasma cortisol and betaendorphin immunoreactivity to surgical stress and postoperative analgesic requirement. Gen Hosp Psychiatry. 1983;5(2):93-8.

28. Parsons HA, Delgado-Guay MO, El Osta B, Chacko R, Poulter V, Palmer JL, Bruera E. Alcoholism screening in patients with advanced cancer: impact on symptom burden and opioid use. J Palliat Med. 2008;11(7):964-8. 
29. Park JE, Kim KI, Yoon SS, Hahm BJ, Lee SM, Yoon JH, Shin WG, Lee HS, Oh JM. Psychological distress as a negative survival factor for patients with hematologic malignancies who underwent allogeneic hematopoietic stem cell transplantation. Pharmacotherapy. 2010;30(12):1239-46.

30. Ozalp G, Sarioglu R, Tuncel G, Aslan K, Kadiogullari N. Preoperative emotional states in patients with breast cancer and postoperative pain. Acta Anaesthesiol Scand. 2003;47(1):26-9.

31. Novy DM, Lam C, Gritz ER, Hernandez M, Driver LC, Koyyalagunta D. Distinguishing features of cancer patients who smoke: pain, symptom burden, and risk for opioid misuse. J Pain. 2012;13(11):1058-67.

32. Naito T, Tashiro M, Yamamoto K, Ohnishi K, Kagawa Y, Kawakami J. Impact of cachexia on pharmacokinetic disposition of and clinical responses to oxycodone in cancer patients. Eur J Clin Pharmacol. 2012;68(10):1411-8.

33. Morita T, Tsunoda J, Inoue S, Chihara S. Contributing factors to physical symptoms in terminally-ill cancer patients. J Pain Symptom Manag. 1999; 18(5):338-46.

34. Mercadante S, Maddaloni S, Roccella S, Salvaggio L. Predictive factors in advanced cancer pain treated only by analgesics. Pain. 1992;50(2):151-5.

35. Mercadante S, Ferrera P, Villari P, Casuccio A, Intravaia G, Mangione S. Frequency, indications, outcomes, and predictive factors of opioid switching in an acute palliative care unit. J Pain Symptom Manag. 2009;37(4):632-41.

36. Mercadante $S$, Ferrera $P$, Villari $P$, Casuccio A. Opioid escalation in patients with cancer pain: the effect of age. J Pain Symptom Manag. 2006;32(5):413-9.

37. Mercadante S, Ferrera P, Casuccio A. Prevalence of opioid-related dysuria in patients with advanced cancer having pain. Am J Hosp Palliat Care. 2011; 28(1):27-30.

38. Mercadante S, Ferrera P, David F, Casuccio A. The use of high doses of oxycodone in an acute palliative care unit. Am J Hosp Palliat Care. 2011; 28(4):242-4.

39. Mercadante S, Dardanoni G, Salvaggio L, Armata MG, Agnello A. Monitoring of opioid therapy in advanced cancer pain patients. J Pain Symptom Manag. 1997;13(4):204-12.

40. Mercadante S, Casuccio A, Pumo S, Fulfaro F. Factors influencing the opioid response in advanced cancer patients with pain followed at home: the effects of age and gender. Support Care Cancer. 2000;8(2):123-30.

41. Mercadante S, Casuccio A, Pumo S, Fulfaro F. Opioid responsiveness-primary diagnosis relationship in advanced cancer patients followed at home. J Pain Symptom Manag. 2000;20(1):27-34.

42. Mercadante S, Casuccio A, Agnello A, Barresi L. Methadone response in advanced cancer patients with pain followed at home. J Pain Symptom Manag. 1999;18(3):188-92.

43. Mercadante S. Switching methadone: a 10-year experience of 345 patients in an acute palliative care unit. Pain Med (Malden, Mass). 2012;13(3):399-404.

44. Mercadante S. Opioid responsiveness in patients with advanced head and neck cancer. Support Care Cancer. 1998;6(5):482-5

45. Makimura C, Arao T, Matsuoka H, Takeda M, Kiyota H, Tsurutani J, Fujita Y, Matsumoto K, Kimura H, Otsuka M, et al. Prospective study evaluating the plasma concentrations of twenty-six cytokines and response to morphine treatment in cancer patients. Anticancer Res. 2011;31(12):4561-8.

46. Lin YL, Lin IC, Liou JC. Symptom patterns of patients with head and neck cancer in a palliative care unit. J Palliat Med. 2011;14(5):556-9.

47. Liang SY, Yates P, Edwards H, Tsay SL. Factors influencing opioid-taking selfefficacy and analgesic adherence in Taiwanese outpatients with cancer. Psycho-Oncology. 2008;17(11):1100-7.

48. Kurita GP, Sjogren P, Ekholm O, Kaasa S, Loge JH, Poviloniene I, Klepstad P. Prevalence and predictors of cognitive dysfunction in opioid-treated patients with cancer: a multinational study. J Clin Oncol. 2011;29(10):1297-303.

49. Kurita GP, de Mattos Pimenta CA. Cognitive impairment in cancer pain patients receiving opioids: a pilot study. Cancer Nurs. 2008;31(1):49-57.

50. Knudsen AK, Brunelli C, Klepstad P, Aass N, Apolone G, Corli O, Montanari M, Caraceni A, Kaasa S. Which domains should be included in a cancer pain classification system? Analyses of longitudinal data. Pain. 2012;153(3):696-703.

51. Knudsen AK, Brunelli C, Kaasa S, Apolone G, Corli O, Montanari M, Fainsinger $R$, Aass N, Fayers P, Caraceni A, et al. Which variables are associated with pain intensity and treatment response in advanced cancer patients?implications for a future classification system for cancer pain. Eur J Pain. 2011;15(3):320-7.

52. Karavelis A, Foroglou G, Selviaridis P, Fountzilas G. Intraventricular administration of morphine for control of intractable cancer pain in 90 patients. Neurosurgery. 1996;39(1):57-61. discussion 61-52
53. Kanbayashi Y, Hosokawa T, Okamoto K, Fujimoto S, Konishi H, Otsuji E, Yoshikawa T, Takagi T, Miki T, Taniwaki M. Factors predicting requirement of high-dose transdermal fentanyl in opioid switching from oral morphine or oxycodone in patients with cancer pain. Clin J Pain. 2011;27(8):664-7.

54. Kaiko RF, Wallenstein SL, Rogers AG, Houde RW. Sources of variation in analgesic responses in cancer patients with chronic pain receiving morphine. Pain. 1983;15(2):191-200.

55. Kaiko RF. Age and morphine analgesia in cancer patients with postoperative pain. Clin Pharmacol Ther. 1980;28(6):823-6.

56. Hwang SS, Chang VT, Fairclough DL, Kasimis B. Development of a cancer pain prognostic scale. J Pain Symptom Manag. 2002;24(4):366-78.

57. Hall S, Gallagher RM, Gracely E, Knowlton C, Wescules D. The terminal cancer patient: effects of age, gender, and primary tumor site on opioid dose. Pain Med (Malden, Mass). 2003:4(2):125-34.

58. Hagen NA, Fisher K, Victorino C, Farrar JT. A titration strategy is needed to manage breakthrough cancer pain effectively: observations from data pooled from three clinical trials. J Palliat Med. 2007;10(1):47-55.

59. Greco MT, Corli O, Montanari M, Deandrea S, Zagonel V, Apolone G. Epidemiology and pattern of care of breakthrough cancer pain in a longitudinal sample of cancer patients: results from the Cancer pain outcome research study group. Clin J Pain. 2011;27(1):9-18.

60. Glare PA, Walsh TD. Dose-ranging study of oxycodone for chronic pain in advanced cancer. J Clin Oncol. 1993;11(5):973-8.

61. Glare P, Walsh D, Sheehan D. The adverse effects of morphine: a prospective survey of common symptoms during repeated dosing for chronic cancer pain. Am J Hosp Palliat Care. 2006;23(3):229-35.

62. Flynn BC, Nemergut EC. Postoperative nausea and vomiting and pain after transsphenoidal surgery: a review of 877 patients. Anesth Analg. 2006;103(1): 162-7. table of contents

63. Flogegard $H$, Ljungman $G$. Characteristics and adequacy of intravenous morphine infusions in children in a paediatric oncology setting. Med Pediatr Oncol. 2003;40(4):233-8.

64. Fallon MT, Hanks GW. Morphine, constipation and performance status in advanced cancer patients. Palliat Med. 1999;13(2):159-60.

65. Fainsinger RL, Nekolaichuk CL, Lawlor PG, Neumann CM, Hanson J, Vigano A. A multicenter study of the revised Edmonton staging system for classifying cancer pain in advanced cancer patients. J Pain Symptom Manag. 2005;29(3):224-37.

66. Fainsinger RL, Nekolaichuk C, Lawlor P, Hagen N, Bercovitch M, Fisch M, Galloway L, Kaye G, Landman W, Spruyt O, et al. An international multicentre validation study of a pain classification system for cancer patients. Eur J Cancer. 2010;46(16):2896-904

67. Droney J, Ross J, Gretton S, Welsh K, Sato H, Riley J. Constipation in cancer patients on morphine. Support Care Cancer. 2008;16(5):453-9.

68. Dougherty M, DeBaun MR. Rapid increase of morphine and benzodiazepine usage in the last three days of life in children with cancer is related to neuropathic pain. J Pediatr. 2003;142(4):373-6.

69. De Conno F, Groff L, Brunelli C, Zecca E, Ventafridda V, Ripamonti C. Clinical experience with oral methadone administration in the treatment of pain in 196 advanced cancer patients. J Clin Oncol. 1996;14(10):2836-42.

70. Collin E, Poulain P, Gauvain-Piquard A, Petit G, Pichard-Leandri E. Is disease progression the major factor in morphine 'tolerance' in cancer pain treatment? Pain. 1993;55(3):319-26.

71. Cohen MR, Pickar D, Dubois M, Bunney WE Jr. Stress-induced plasma betaendorphin immunoreactivity may predict postoperative morphine usage. Psychiatry Res. 1982;6(1):7-12.

72. Chow E, Connolly R, Wong R, Franssen E, Fung KW, Harth T, Pach B, Andersson L, Schueller T, Stefaniuk K, et al. Use of the CAGE questionnaire for screening problem drinking in an out-patient palliative radiotherapy clinic. J Pain Symptom Manag. 2001;21(6):491-7.

73. Cherny NI, Thaler HT, Friedlander-Klar H, Lapin J, Foley KM, Houde R, Portenoy RK. Opioid responsiveness of cancer pain syndromes caused by neuropathic or nociceptive mechanisms: a combined analysis of controlled, single-dose studies. Neurology. 1994;44(5):857-61.

74. Candrilli SD, Davis KL, lyer S. Impact of constipation on opioid use patterns, health care resource utilization, and costs in cancer patients on opioid therapy. J Pain Palliat Care Pharmacother. 2009;23(3):231-41.

75. Bruera E, Schoeller T, Wenk R, MacEachern T, Marcelino S, Hanson J, SuarezAlmazor M. A prospective multicenter assessment of the Edmonton staging system for cancer pain. J Pain Symptom Manag. 1995;10(5):348-55. 
76. Bercovitch M, Waller A, Adunsky A. High dose morphine use in the hospice setting. A database survey of patient characteristics and effect on life expectancy. Cancer. 1999;86(5):871-7.

77. Bercovitch M, Adunsky A. High dose controlled-release oxycodone in hospice care. J Pain Palliat Care Pharmacother. 2006;20(4):33-9.

78. Bercovitch $M$, Adunsky A. Patterns of high-dose morphine use in a homecare hospice service: should we be afraid of it? Cancer. 2004;101(6):1473-7.

79. Appelgren L, Nordborg C, Sjoberg M, Karlsson PA, Nitescu P, Curelaru I. Spinal epidural metastasis: implications for spinal analgesia to treat "refractory" cancer pain. J Pain Symptom Manag. 1997;13(1):25-42.

80. Życzkowska JGT, Kleja J, Filipczak-Bryniarska I, Wrzosek A, Wordliczek J. Age influence on opioid consumption in terminally ill digestive cancer patients. Medycyna Paliatywna w Praktyce. 2013;7(2):50-4.

81. Radha Krishna LK, Poulose JV, Tan BS, Goh C. Opioid use amongst cancer patients at the end of life. Ann Acad Med Singap. 2010;39(10):790-7.

82. Pina $P$, Sabri E, Lawlor PG. Characteristics and associations of pain intensity in patients referred to a specialist cancer pain clinic. Pain Res Manag. 2015; 20(5):249-54.

83. YE-T LM-H, Huang S-C, Wang H-M, Su W-R, Lai Y-L. Clinical experience with strong opioids in pain control of terminally ill Cancer patients in palliative care settings in Taiwan. J Exp Clin Med. 2010;2(6):292-6.

84. Kurita GP, Lundstrom S, Sjogren P, Ekholm O, Christrup L, Davies A, Kaasa S, Klepstad P, Dale O. Renal function and symptoms/adverse effects in opioidtreated patients with cancer. Acta Anaesthesiol Scand. 2015;59(8):1049-59.

85. Gagnon P, Allard P, Masse B, DeSerres M. Delirium in terminal cancer: a prospective study using daily screening, early diagnosis, and continuous monitoring. J Pain Symptom Manag. 2000;19(6):412-26.

86. Edrington JM, Paul S, Dodd M, West C, Facione N, Tripathy D, Koo P, Schumacher K, Miaskowski C. No evidence for sex differences in the severity and treatment of cancer pain. J Pain Symptom Manag. 2004;28(3):225-32.

87. Bergman P, Sperneder S, Hoijer J, Bergqvist J, Bjorkhem-Bergman L. Low vitamin D levels are associated with higher opioid dose in palliative cancer patients-results from an observational study in Sweden. PLoS One. 2015; 10(5):e0128223.

88. Arthur J, Yennurajalingam S, Nguyen L, Tanco K, Chisholm G, Hui D, Bruera E. The routine use of the Edmonton classification system for Cancer pain in an outpatient supportive care center. Palliat Support Care. 2015;13(5):1185-92.

89. Anghelescu DL, Snaman JM, Trujillo L, Sykes AD, Yuan Y, Baker JN. Patientcontrolled analgesia at the end of life at a pediatric oncology institution. Pediatr Blood Cancer. 2015;62(7):1237-44.

90. Anghelescu DL, Zhang K, Faughnan LG, Pei D. The safety and effectiveness of patient-controlled analgesia in outpatient children and young adults with Cancer: a retrospective study. J Pediatr Hematol Oncol. 2015;37(5):378-82.

91. Goksu SS, Bozcuk H, Uysal M, Ulukal E, Ay S, Karasu G, Soydas T, Coskun HS, Ozdogan M, Savas B. Determinants of opioid efficiency in cancer pain: a comprehensive multivariate analysis from a tertiary cancer Centre. Asian Pac J Cancer Prev. 2014;15(21):9301-5.

92. Dahan A, Overdyk F, Smith T, Aarts L, Niesters M. Pharmacovigilance: a review of opioid-induced respiratory depression in chronic pain patients. Pain Physician. 2013;16(2):E85-94.

93. Pleym H, Spigset O, Kharasch ED, Dale O. Gender differences in drug effects: implications for anesthesiologists. Acta Anaesthesiol Scand. 2003;47(3):241-59.

94. Niravath P. Aromatase inhibitor-induced arthralgia: a review. Ann Oncol. 2013;24(6):1443-9.

95. Kain ZN, Mayes LC, Caldwell-Andrews AA, Karas DE, McClain BC Preoperative anxiety, postoperative pain, and behavioral recovery in young children undergoing surgery. Pediatrics. 2006;118(2):651-8.

96. Mercadante S. Pharmacotherapy for breakthrough cancer pain. Drugs. 2012; 72(2):181-90.

97. Fallon MT. Neuropathic pain in cancer. Br J Anaesth. 2013;111(1):105-11.

98. Younger J, McCue R, Mackey S. Pain outcomes: a brief review of instruments and techniques. Curr Pain Headache Rep. 2009;13(1):39-43.

99. WHO guidelines on the pharmacological treatment of persisting pain in children with medical illnesses. http://apps.who.int/iris/bitstream/handle/ 10665/44540/9789241548120 Guidelines.pdf. Accessed 23 Apr 2018

\section{Ready to submit your research? Choose BMC and benefit from:}

- fast, convenient online submission

- thorough peer review by experienced researchers in your field

- rapid publication on acceptance

- support for research data, including large and complex data types

- gold Open Access which fosters wider collaboration and increased citations

- maximum visibility for your research: over $100 \mathrm{M}$ website views per year

At BMC, research is always in progress.

Learn more biomedcentral.com/submissions 